\title{
Artificial Intelligence for the Financial Services Industry: What Challenges Organizations to Succeed
}

\author{
Luisa Kruse \\ Goethe University Frankfurt \\ luisakruse@hotmail.com
}

\author{
Nico Wunderlich \\ Goethe University Frankfurt \\ nwunderlich@wiwi.uni-frankfurt.de
}

\author{
Roman Beck \\ IT University of Copenhagen \\ romb@itu.dk
}

\begin{abstract}
As a research field, artificial intelligence (AI) exists for several years. More recently, technological breakthroughs, coupled with the fast availability of data, have brought AI closer to commercial use. Internet giants such as Google, Amazon, Apple or Facebook invest significantly into AI, thereby underlining its relevance for business models worldwide. For the highly data driven finance industry, AI is of intensive interest within pilot projects, still, few AI applications have been implemented so far. This study analyzes drivers and inhibitors of a successful AI adoption in the finance industry based on panel data comprising 22 semi-structured interviews with experts in AI in finance. As theoretical lens, we structured our results using the TOE framework. Guidelines for applying AI successfully reveal AI-specific role models and process competencies as crucial, before trained algorithms will have reached a quality level on which AI applications will operate without human intervention and moral concerns.
\end{abstract}

\section{Introduction}

Recent technological developments and the emergence of big data have led to an increasing interest in artificial intelligence (AI) worldwide. Some even propagate "AI first" as a mantra and symbol for a massive disruption of business models, leading to fundamentally new markets [12]. Internet giants such as Google, Amazon, Apple or Facebook are investing millions in AI to provide AI-based applications and services, which underlines the relevance of AI for all kinds of different businesses [20]. AI's impact on productivity could be transformative, as several industry studies imply: According to a recent study published by $\mathrm{PwC}$, global GDP will rise by $14 \%$ until 2030 resulting from the use, development, and adoption of AI systems, which equals additional \$15.7 trillion [24].

Nowadays, technological progress in various areas combined with the availability of huge amounts of structured and unstructured data is a significant leap forward to harvest the potential of AI for business applications [26]. According to the World Economic Forum, AI start-ups rose from $\$ 282$ million in 2011, to \$2.4 billion in 2015 [28]. Google, Amazon, Tesla, and Facebook are regularly publishing their AI libraries, forcing their accessibility to a broad mass of developers. In addition, tools for integrating AI are now offered by many major software vendors, e.g. Salesforce Einstein, IBM Watson or Microsoft LUIS, which allow to take AI out of the labs and into production and use by companies [26]. With the advent of AI illustrated by the mentioned Internet giants, $\mathrm{AI}$ is now permeating all kinds of other industries, including finance.

Besides, the popularity of $\mathrm{AI}$ is a direct response to the ever increasing amount of "big data", that asks for new ways of data analytics to capture value for businesses. AI allows for pattern recognition and smarter ways of data utilization in an automated way, leading to an improved intelligence about customer needs and markets, which in turn leads to competitive advantages [12].

The financial services (FS) industry shows great potential for AI, since data, more specifically customer and transaction data, is the main resource, which banks and insurance companies continuously collect, sort, process and link [15]. A range of FS companies are starting to launch chatbots or robo-advisors, often in their mobile apps or on social media. The German insurance company VHV Versicherungen, for instance, has just recently released its new chatbot "Mia" to improve customer support [21]. Deutsche Bank, for instance, is the first affiliate bank in Germany with a digital asset manager called "Robin" (abbreviation of robo-invest) [17]. Accenture estimates baseline growth of the finance sector with AI technologies at $\$ 4.6$ trillion until 2035.

In principle, the business models of financial institutions are completely digitizable; the emergence of $21^{\text {st }}$ century digital born financial technology companies (FinTechs) as well as increases in customer demands in the same line put pressure on the incumbent finance sector. Thus, in this study we are interested in: 
How finance institutions deal with the need for adapting and adopting AI and how they are coping with related challenges.

To answer our question, we interviewed a panel of AI experts from the German finance industry and supporting sectors and used the TOE framework as guiding theoretical framework. The qualitative empirical data was collected through semi-structured expert interviews, including interviews with experts from leading software providers in the finance industry (such as SAP, IBM, Salesforce, and Microsoft), supplemented by interviews with experts at $\mathrm{CxO}$ level. Having analyzed the main challenges associated with AI based on the collected qualitative interview data, we answer each challenge with a respective guideline as second level within the investigation. This analysis highlights the importance of AI for banks and insurance companies to stay competitive while they have to overcome traditional organizational structures and lacking service mentalities to achieve the intended benefits.

\section{Artificial Intelligence and the Financial Services Industry}

In the finance industry, banks and insurance companies operate in a complicated, competitive business that is facing significant transformation pressure to stay in the market. In this environment, sustaining customer loyalty, which comprises satisfaction, trust, commitment, and perceived value, plays a cental role [3].

Data giants such as Google, Facebook and Apple have already proven that consistent focus on customers and the use of modern technologies can redefine financial service processes. However, traditional FS providers often do not offer enough flexibility and innovation strengths for their clients. FinTech is therefore embraced as a game-changing disruptive innovation capable of breaking up traditional financial markets [18]. Making use of modern, state-of-the-art technologies, these market partipiciants do not build up on legacy architectures. Through lean and agile processes, FinTechs are able to achieve greater customer orientation, lower costs, and accelerating the speed of innovation. These companies, mostly entrepreneurial, have driven major innovations in numerous areas such as payment, wealth management, lending or crowdfunding [18] and have also spurred the adoption of AI and machine learning in FS [28].

The presence of digital born FinTechs, whose business is strongly customer-oriented, forces traditional companies in the financial market to change: At the intersection between customers and institutes, the amount of continously computed information shows great potential for evaluation, analysis, and product recommendations. A redesign of digital experiences highlights conversational interfaces reshaping from a form-based (rigid default fields or complex forms) to a conversation-based communication: AI provides an opportunity for consumers to interact with companies in a more natural way through writing, talking or even gesturing [11]. Further, the customer segment of socalled digital natives (generations from 1995 onwards) [27] expects experiences from the FS providers similar to those gained with Facebook, Apple, or other digital suppliers. This encompasses easy-to-understand financial products, a very sophisticated arrangement of all information, optimized processes with short throughput, and the adaptability of the product or service to the customer's own needs before and after purchase (customization) [27].

Within this study, the consultation of banks and insurance companies, as well as software vendors emphasizes the accumulation of customer-focused utilization of AI. Though, our analysis identifies that most companies are developing first prototypes of AI, which have rarely been implemented by the FS industry yet. For the most part, prototypes are developed in a clinical environment and for internal use only, in order to identify and test possible use cases (cf. I12.6, I8.4). These cover front office applications such as credit scoring, insurance, or client-facing chatbots. Chatbots or virtual assistants represent one of the few uses carried out by AI interfaces, which are already implemented within banks and insurance companies (cf. I22.5). However, participants complain about the simplicity of today's chatbots and appear rather disappointed with the current applications (cf. I14.8, I4.11). This valuation confirms the classification within financial stability report, which describes current generation of chatbots as simple and as providing general policy information or answers to basic questions [28].

Especially the subgroup of technology industry experts emphasizes the importance of operations-focused appliance, as back-end operations and risk management require a lot of inefficient human support and are often inefficient (chapter 4.2). AI technologies offer potential for cost savings and higher productivity in the financial sector through intelligent process automation and automated customer services. As a result, opportunities arise for enhanced customer experience and engagement, e.g. through faster response times and individualized offerings, which may lead to increased sales and higher revenues. In order to remain competitive and to retain public trust, traditional institutions in finance have to initiate to rely on $\mathrm{AI}$ in bits and pieces.

Describing the complexity of AI, countless attempts exist to define the term AI, encompassing a huge variety of subfields and with different focus depending on the respective technical and historical 
origin [12]. For the purpose of this study, artificial intelligence is defined as "how to make computers do things at which, at the moment, people are better" [26]. The ability to adapt to different environments and learn to change behavior accordingly is still a particular strength of human beings but one that is now under threat by machine learning (ML) advances, which is mainly responsible for the current "AI euphoria" [12]. As an essential part of AI, ML refers to the ability of systems or applications that learn without being explicitly programmed [10]

\section{The Technology-Organization- Environment Framework (TOE)}

To gain a comprehensive view on the challenges of AI adoption within the German finance industry, this study builds upon the TOE framework developed by Tornatzky and Fleischer in 1990 in the context of technological innovation [29]. The TOE framework is an organization-level theory, which presents the three elements technology, organization, and environment, influencing the process to adopt and implement technology within a firm [4] and has achieved solid empirical approval in analyzing the context of innovations [8]. The technology context describes internal as well as external technologies relevant to the firm [31]. Internal technologies refer to the firms existing technologies, which set a broad limit on the pace and scope of technological change that a firm can undertake, while external technologies refer to the availability of new technologies within the market. A range of measures characterizes the organizational context, including but not limited to the size of the firm, its managerial structures, and human resources [4]. The structures and regulatory environment of the respective industry are represented by the environmental context in which a firm conducts its business. This dimension of the framework includes factors such as the firm's competitors, customers, the government, as well as the community are taken into account [31].

The study at hand focusses on the finance industry, which has received limited attention within research in the context of AI so far. However, the finance industry has been investigated by means of the TOE framework in various other domains. Zhu et al. (2004) for example studied e-business adoption in the finance industry applying the TOE framework in order to structure survey data from 612 firms in 10 countries [31]. Another more recent study analyzes the value-based adoption of big data analytics using the TOE framework, which is a subject area closely related to the field of AI [30]. The study outlines the main reasons for non-adoption of big data analysis, using a similar approach as our investigation. Therefore, we deem the TOE framework as an appropriate theoretical background for investigating the challenges of AI adoption for the FS industry.

\section{Data Analysis and Results}

The goal of this investigation is to understand which challenges banks and insurance companies face in order to adopt $\mathrm{AI}$ and to provide guidelines how to answer these challenges. In the following, first the main challenges associated with the adoption of AI within the German finance industry are extracted from the executed data collection; second, guidelines are derived from both interview results and further extant scientific literature. Following the TOE framework, this section is structured into the three dimensions technology, organization, and environment. The experts' statements build up the respective chapters of the TOE dimensions: During the analysis, the TOE framework revealed as an appropriate theoretical based structuration since all relevant aspects in a firm's context are embraced. Analyzing the qualitative data, we refer to the interview (Ix) and the corresponding text passage (.xx) when presenting the results, as follows: (cf. Ix.xx).

\subsection{Challenges in AI Adoption Based on the TOE Framework}

4.1.1. Technology context. As one main result, two-thirds of the interviewees state a lack in the availability and quality of training data as prohibiting further AI adoption, which prevents FS firms from using these AI enhanced solutions or products (cf. I12.4). The perceived lack in data quality in our sample derives from an immanent AI characteristic: the algorithm learns from exposure to known examples of input and output data, which means the way an AI system fulfills its purpose is trained. Therefore, AI requires huge amounts of training data. As the interviews reveal, a lack of sufficient of digitally available data exists to train an AI system appropriately; or if so, data privacy issues prevent firms from using this data (cf. I12.4). Although data, more specifically customer and transaction data, is the resource which banks and insurance companies collect, sort, process and link, the shortage of AI training data can be traced back to the fact that many established FS providers are still set up analogical in their core: Still, many business processes are still too paper-based, reducing the actual amount of digitally available data.

Furthermore, some of the experts claim a lacking market overview as prohibiter in enhancing data quality. This is more surprising since today AI engines are 
offered by all large software providers such as Microsoft' LUIS, IBM Watson, Amazon Lex, SAP Leonardo, or Salesforce Einstein. Complementary, a large number of providers exist who enjoy high visibility in the market as start-ups (cf. I20.5, I6.3, I12.3).

The interviews reveal that the existing IT architectures often form a legacy ballast which is difficult to reform and which limits digital transformation and therefore the use of AI (cf. I20.6). The study finds that several difficulties for businesses in implementing AI algorithms exist, which reflects the companies exiting IT infrastructures as well as AI's respective technological characteristics. Legacy ballast refers to IT architectures, which have been gradually expanded since the 1980s but often have not been continuously renewed. The current status lowers the speed of innovation and binds financial as well as personal resources (cf. I21.11).

In addition, the analysis of the interviews identifies a major challenge for banks and insurance companies to achieve levels of quality assurance in AI-supported decisions (cf. I20.13, I17.13). Still, it is desirable that AI results, e.g., calculations, forecasts, and following processes or decisions of information systems, are transparent and comprehensible. As mentioned, the AI based systems' intent is programmed, but the process to fulfill its purpose is trained. Products or processes with included AI components will therefore act differently over time. This also implies specific risks for businesses, which include for example biases in training data. The benefit of an AI solution is highly dependent from its prior training. As structural biases of training data lead to unwanted outcomes, data quality defects need to be identified and eliminated quickly. Further, the AI itself, its training data, or the user might generate output that is not aligned with ethical standards. To describe this lack of continuous high quality level AI output, the decision-making process of an AI solution is often compared to a "black box" with little to non-transparency (cf. I8.11, I17.13). Thus, further control mechanisms need to be established to monitor the AI's behavior and its compliance to existing regulations and standards. Especially, a major challenge for FS is therefore, to build trust and transparency into AI solutions to leverage its full potential.

Structuring our findings by means of the technological context leads to the following results:

1 Banks and insurance are challenged by providing the respective quantity and quality of the data an AI system needs to create value for the enterprise.

2 Since AI engines are offered amongst all big tech companies, the market transparency and pure availability of technology providers cannot be identified as slowing down AI adoption within FS.
3 With regard to the company's existing IT architecture, the study shows that the maintenance of exiting IT architectures lowers the speed of innovation and binds financial as well as personal resources.

4 Referring to the factor of technological characteristics, the study finds that the lack of transparency into the AI "black box" is often met with reserve and leads to a slow AI transition (cf. I20.13).

Table 1. Challenges structured within the TOE framework in allusion to Tornatzky and Fleischer (1990)

\begin{tabular}{|l|l|}
\hline \multicolumn{2}{|l|}{ Technological context } \\
\hline $\begin{array}{l}\text { Technological } \\
\text { readiness }\end{array}$ & $\begin{array}{l}\text { 1 Availability and quality of training data } \\
\text { 2 Vague market: Availability of AI enhanced } \\
\text { products and solutions for banks and insurance } \\
\text { companies } \\
\text { 3 Extant IT infrastructures as prohibitor }\end{array}$ \\
\hline $\begin{array}{l}\text { AI Character- } \\
\text { istics }\end{array}$ & $\begin{array}{l}\text { 4 AI specific characteristics, which most im- } \\
\text { portantly refer to its lack of transparency } \\
\text { ("black box"): risk, compliance, and ethical } \\
\text { standards of AI made decisions }\end{array}$ \\
\hline Organizational context \\
\hline $\begin{array}{l}\text { Organizational } \\
\text { readiness }\end{array}$ & $\begin{array}{l}\text { 1 Professional expertise in AI skills } \\
\text { 2 Hierarchical structures and willingness to } \\
\text { change of the employees } \\
\text { 3 Changing process competencies } \\
\text { 4 Agility to adapt firms resources (financial, } \\
\text { technical, human) }\end{array}$ \\
\hline $\begin{array}{l}\text { Top- } \\
\text { management } \\
\text { support }\end{array}$ & $\begin{array}{l}\text { 5 Support of the top management in the adop- } \\
\text { tion of AI technologies }\end{array}$ \\
\hline Environmental context \\
\hline $\begin{array}{l}\text { Industrial } \\
\text { Characteristics }\end{array}$ & $\begin{array}{l}\text { 1 Traditional data protection as part of core } \\
\text { business } \\
\text { 2 Competitive environmental pressures } \\
\text { (FinTechs) } \\
\text { 3 Lacking customers and community support } \\
\text { driven by moral concerns and uncertainty }\end{array}$ \\
\hline $\begin{array}{l}\text { Governmental } \\
\text { Regulations } \\
\text { documentation and regulatory reporting } \\
\text { Competitive pressures as government regula- } \\
\text { tion opens up for new entries (PSD2) }\end{array}$ \\
\hline
\end{tabular}

4.1.2. Organizational context. Most importantly, the experts state that organizations are facing a severe knowledge gap regarding digital skills of their workforce (cf. I4.14, I8.15). According to the group of banks and insurance companies in particular, job profiles such as Data Scientists or so-called Requirement Engineers are desperately needed (cf. I11.13). Additionally, many of the surveyed experts outline that in the future, it will be less a question of hard skills, but instead the mindset and the willingness of employees to change will play a much greater role (cf. I17.11, I10.11). The challenge in this context is constituted by how employees can be enabled to increasingly focus 
on problem-solving tasks and implementing activities (cf. I12.11, I10.11, I17.11).

Accelerating for digitization and AI adoption also leads to the fact that companies have less need for certain types of work roles and consequently more demand for changing process competencies, according to the surveyed experts. The study outlines that operational changes are visible in the following areas, where AI deployment is particularly promising: A) situation recognition, B) decision support and C) development and forecast. According to our analysis, these activities, which can be classified as routine activities, will no longer be in demand on the labor markets with the use of AI technologies (cf. I22.12). Further, conceivable sales tasks or standard advice step into the light, since digital assistants allow automated interactions with customers (cf. I3.18, I19.2).

Another challenge especially for banks and insurance companies identified by the experts aims at bridging the gap between legacy and digital operations, as the former often hinders or sub-optimizes valuable investments in the latter [2]. The study finds that culturally rewriting this friction is a necessary prerequisite for creating value through AI technologies (cf. I21.11).

On the other hand, some participants state that as long as digital natives have not yet reached top management positions, there will be hardly any change in the established structures of the companies and new technologies will continue to collide with old ways of thinking (cf. I12.4). Top management support can therefore be identified as an important factor for successful AI adoption (cf. table 1).

Summing up, the collected arguments indicate organizational readiness as well as top-management support as major factors for innovation adoption within the TOE framework (cf. table 1). Based on our results, both elements are strongly supported within the arena of AI:

1 Skills and technological knowledge appear to be most important and at the same time the most challenging aspect with regard to a successful AI adoption. This is even more a relevant finding, since this factor was excluded from previous studies on IS adoption. This factor suggests to question how to enable employees to fulfill higher quality tasks, since the experts claim that companies will have less need for certain types as computers get more powerful.

2 Willingness to change of the firms' employees and changing process competencies reflect major challenges for banks and insurance companies. People have to leave their accustomed environment, learn to work more closely with other departments and to deal with an artificially intelligent system.
3 Speed in processes, as well as the continuous training and the associated risks of an AI system require higher agility and faster adaptability within the enterprise and its employees

4 Hierarchical organizational structures and missing top-management support across processes forestall the required agility and adaptability with regard to the implementation of AI enhanced solutions.

4.1.3. Environmental context. AI requires massive data analysis, which can only be realized by moving data into decentralized data centers, namely "the cloud". The surveyed expert find that the FS industry is still concerned about losing control on their own data, since this data is the core value of their business (cf. I17.6). In addition, security breaches, data leaks, and unauthorized access to data that is used for training of AI or is utilized as input data for it, need to be avoided, since it has significant impact on the output of the AI system. For these reasons, data protection issues have been identified as a major challenge for AI adoption within the finance industry (cf. I18.3, I1.13).

For the finance industry, the results provide market disruption by FinTechs on the other hand as accelerating AI adoption within the FS industry. The emergence of FinTechs forces established FS provider to change, as FinTechs especially benefit from their leanness, agility, and innovation strengths [18]. Especially within the banking sector, FinTechs put pressure on the established firms to optimize their processes, systems, and products (cf. I20.8).

Distancing from the previous finding, the surveyed experts further outline that especially traditional financial providers are confronted with a huge number of regulatory requirements, which ties up personal as well as financial resources (cf. I10.7). Documentation and regulatory reporting force FS providers to invest heavily. Consequently, there is only few budget left that can be allocated to digital transformation projects such as AI (cf. I10.7). Regulatory requirements include, for example, requirements in risk departments (BCBS239); further regulations exist on the market side, such as the Market in Financial Instruments Directive (MiFID) and MiFID II (effective on the 3rd of January 2018), both aiming to restore trust in the financial markets [16]. At the same time, governments' market regulation provides a generous regulatory environment for FinTechs in order to stimulate global financial innovation and competitiveness [18], e.g. the Payment Services Directive 2 (PSD2) that requires banks to give other financial service providers and socalled third-party providers access to their customer data.

The surveyed experts further claim that moral concerns and uncertainty challenge AI adoption and em- 
phasize the importance of the development of moral and ethical frameworks. Dealing with hopes and fears of new technological innovations and shaping this phase of change well is a major challenge within society (cf. I6).

The previous findings support the environmental context as the third critical TOE dimension for innovation adoption (cf. table 3). Since the global financial crisis, the FS landscape faces an increase in risk awareness as well as regulatory intervention and regulatory requirements [15]. A study by Zhu et al. (2004) found that government regulations play a significant role in the adoption process of e-business [31], while the current investigation finds similar results with regard to AI adoption:

1 Traditional data protection is part of the core business of the finance industry

2 On the other hand, the emergence of FinTechs spurs traditional FS provider to change.

3 Regulatory requirements such as BCBS239 or MiFID exceedingly cohere financial and personal resources of finance institutes. At the same time, government regulation opens up for new market entries.

4 Moral concerns are slowing down the pace of AI adoption

\subsection{Practical Guidelines for AI Adoption}

In the context of the TOE framework, this study identifies several challenges for the FS industry with regard to successful AI adoption, which resulted from the data analysis. We will now discuss practical recommendations based on the lesssons learned from the analyzed AI projects on how to move forward with AI in finance, therby exactly answering the respective challenge identified within the respective TOE context presented in the previous chapter 4.1 .

4.2.1. Technological implications. Our study finds that the lack in data quantity and quality is highly underestimated when it comes to AI deployment and represents a major challenge for the finance sector. The immense benefit from an AI system is highly dependable to its prior training. ML always requires prior input and output data for the initial learning process and a sufficient amount of available data to train the system. How much "sufficient" actually is, depends on a variety of factors such as complexity of data, type of task and many more [25]. Therefore, companies need to make sure the data needed is digitally available and if so, the data is on a quality level where it can be used to draw value-adding conclusions.

In addition, legacy ballast of extant IT architectures, analogue business processes, and the resulting lack in data quality reduces the speed of innovation in the FS, therefore promoting the use of modern IT architectures, so-called services oriented architectures (SOA) [13]. Based on the collected data, we recommend the use of micro services, which were proved of particular importance herein, offering flexibility than monolithic IT architectures (cf. I20.6). Micro services refer to stand alone software modules that contain only one single function [5], which place demands on the agility of the organization and infrastructure of development (cf. I20.6). With regard to a companies' entire IT infrastructure, these changes imply an IT of two speeds ("2-speed IT"): The traditional IT infrastructure keeps operating, designed for security and stability of the core banking/insurance system - complemented by a second infrastructure supporting fast and flexible application development and deployment [23].

Providing recommendations for the specific technological AI characteristics, the "black box" functionality of an AI system requires quality assurance, which sounds like a contradiction in itself. However, in order to succeed with further adoption of AI, banks and insurance companies need to make a system trustable and explainable, resulting in specific AI governance and control. The analyzed risk complex demands for AI adapted risk management. Further, the compliance requirements need to be fulfilled, especially for systems operating "live" and direct in customer interaction, e.g. to avoid the documented ethical violations (cf. I14). Where technological, data based training on the current level reaches its limit, organizational structures, meaning human intervention, is required. Therefore, the solution to this need to be addressed within the organizational context. Subsequently organizational consequences are discussed in the following.

To conclude and with regard to a successful AI adoption and deployment, our study suggests guidelines for banks and insurance companies in the technological context (cf. table 2, technological context):

1 Ensure sufficient training data and avoid biases and inconsistencies in training data structure

2 Achieve an extended market overview on AI providers (e.g. through consulting services)

3 Modernize their IT architectures (SOA and 2speed IT) and deploy micro services (only feasible for already digitally advanced organizations)

4 Develop quality assurance systems

4.2.2. Organizational implications. Based on our analysis, we highly recommend companies to maintain a workforce with AI related skills. Skill development as well as technology enablement among existing employees plays a major role with regard to successful AI adoption. However, hiring additional employees with professional expertise in AI or bordering fields appears 
appropriate. Within the existing traditional top-down hierarchy, there is little focus on nontraditional and new types of stakeholder, and small room for employees to change [2]. We therefore recommend firms to consider constellations such as the incubator model known from innovation management, which is likely to experience an increased usage in the course of AI [16]. In business context, people refer to this model as Digital Labs or Digital Units, ideally, combining ifferent roles and skills, such as data privacy, legal, IT and business (cf. I14.17). Employees operate without hard pressure on results and fixed deadlines, instead focussing on innovative prototypes and solutions (cf. I12.6).

Table 2. Practical guidelines structured within the TOE framework in allusion to Tornatzky and Fleischer (1990)

\begin{tabular}{|c|c|}
\hline \multicolumn{2}{|c|}{ Technological context } \\
\hline $\begin{array}{l}\text { Technological } \\
\text { readiness }\end{array}$ & $\begin{array}{l}1 \text { Ensure sufficient training data by evaluating } \\
\text { each use case carefully, also avoid structural } \\
\text { biases in training data } \\
2 \text { Extended market analysis to achieve en- } \\
\text { hanced market overview of AI products and } \\
\text { solutions } \\
3 \text { Modernize IT architectures (SOA and 2- } \\
\text { speed IT) and deploy micro services }\end{array}$ \\
\hline $\begin{array}{l}\text { AI Character- } \\
\text { istics }\end{array}$ & $\begin{array}{l}4 \text { Our solution for the AI "black box" charac- } \\
\text { teristics mainly refers to the organizational } \\
\text { context; from a technological perspective, } \\
\text { improved algorithms (again highly dependable } \\
\text { on previous training) would benefit the prob- } \\
\text { lem }\end{array}$ \\
\hline \multicolumn{2}{|c|}{ Organizational context } \\
\hline $\begin{array}{l}\text { Organizational } \\
\text { readiness }\end{array}$ & $\begin{array}{l}\mathbf{1} \text { Develop and hire AI professional skills } \\
\mathbf{2}+\mathbf{3} \text { Create a working environment for new } \\
\text { hires AND existing employees where they can } \\
\text { promote technological innovation and over- } \\
\text { come hierarchical structures } \\
\mathbf{3} * \text { Reacting to the "black box" phenomenon, } \\
\text { guarantee ethical standards by AI governance: } \\
\text { AI risk management \& AI compliance man- } \\
\text { agement } \\
\mathbf{4} \text { Further promote agility to adapt firms re- } \\
\text { sources (financial, technical, human) }\end{array}$ \\
\hline $\begin{array}{l}\text { Top- } \\
\text { management } \\
\text { support }\end{array}$ & $\begin{array}{l}5 \text { Create awareness in top management posi- } \\
\text { tions to alloctae budget in order to fundamen- } \\
\text { tally modernize and digitize their business - } \\
\text { top management support enables and stimulates } \\
\text { organizational change }\end{array}$ \\
\hline \multicolumn{2}{|c|}{ Environmental context } \\
\hline $\begin{array}{l}\text { Industrial } \\
\text { Characteristics }\end{array}$ & $\begin{array}{l}\text { 1+2 By making AI explainable and valuable, } \\
\text { firms will overcome traditional data protection } \\
\text { and utilize extant proprietary data resources to } \\
\text { compete with FinTechs } \\
\mathbf{3} \text { As an ethical framework, AI code of conduct } \\
\text { serves to build trust in AI. This may influence } \\
\text { and desensationalize public discourses around } \\
\text { moral concerns about AI }\end{array}$ \\
\hline $\begin{array}{l}\text { Governmental } \\
\text { Regulations }\end{array}$ & $\begin{array}{l}4 \text { Financial institutions must achieve space for } \\
\text { innovation within their working environment } \\
\text { and despite governmental regulations }\end{array}$ \\
\hline
\end{tabular}

Since AI is able to learn independently, the systematic weaknesses of AI systems, such as intuition or variability, which will remain short-term to mid-term in a change of work roles executed by humans within business processes of many tasks. The more complex the decision-making situation, the more human judgment must be involved in the process (cf. I11.12The study finds that a central prerequisite for an AIoriented working environment is therefore not only to promote AI, but also human intelligence (cf. I10.10, I5.8). Society and firms need to massively invest in digital education, information literacy and the courage in making one's own judgements and decisions at all levels of education to fulfil the demand of changing process competencies in order to make the interaction between humans and machines a success (cf. I10.10). Especially reflecting the changing process competencies from the organizational challenges and ensuring for AI specific data quality of training algorithms, many interviewees for instance consider the position of an "AI Trainer", who would be involved in the development and improvement of an AI system during ongoing operations (cf. I10.17). Since there is no other technology like AI fulfilling its purpose trained rather than programmed, this poses an innovative position within IT (cf. I10.17.). In reference to the challenging AI black box mechanism, we find that an AI Trainer could be the first instance to improve government as well as risk management and therefore promote trustable and explainable AI.

The study further finds that companies, which want to rely on AI competencies in their processes and resulting products in future, will experience a considerable acceleration of their business processes and/or product lifecycles through higher automation (cf. I12.1). Speed in processes, as well as the continuous training and the associated risks of an AI system require higher agility and faster adaptability of the enterprise and its employees. For example, a customer does not usually respond to an e-mail as quickly as to a chat: In other words, a simple AI-supported chat bot is nice to have, but consequently all related processes within the organization must also be accelerated (cf. I20.9). Otherwise, the added value is questionable, leading to frustration on the end user side.

We further suggest that consulting companies to create awareness for top management support resulting in banks and insurers spending money in order to fundamentally modernize and digitize their business. The role of the Chief Digital Officer (CDO) is from particular importance here and, as a "next step" expanding the role of the AI-Trainer, a Chief Artificial Intelligence Officer (C"AI"O) is increasingly being discussed amongst large enterprises, intending to link and optimize existing operations with new digital components 
such as machine learning, develop AI strategies, or transforming unused data silos for the use with AI [12].

To conclude, in the organizational context banks and insurance companies should consider:

1 Develop AI-related skills of existing employees within the firm and hire further professional skills

$2+3$ Create a working environment to experience with digital innovations. Firms need to overthink their traditional top-down hierarchy and promote innovative working models. (e.g. Digital Labs/Units)

3* To enhance transparency and control of the AI ("black box"), guarantee ethical standards: AI risk management, AI compliance management, AI governance. The solution to this technological challenge can be addressed by creating new roles in the workplace, e.g. an AI Trainer.

4 Understand that AI does not exist in a vacuum. Its capabilities will be intervened with the development of all other technological innovation and require agility and speed in processes.

5 Companies need to create awareness and positions for top management support for the importance of modernizing and digitizing their business (e.g. through consulting or the development of CDO or a C'AI"O)

4.2.3. Environmental implications. In media, AI is often burdened with negative associations such as massive unemployment or dangerous super-intelligent robots, much of which is science fiction. To a large extent, AI-based algorithms learn independently from huge amounts of available data. The example of $\mathrm{Mi}$ crosoft Tay shows that this can sometimes go in the wrong directions and the concerns regarding AI are not unjustified. Tay, a chatbot built by Microsoft, was exposed to the Facebook community in order to be trained by them without any control from its owners. Within just one day, it had posted radical right-wing and sexist statements so it had to be taken off the internet immediately [12]. In order not to further stir up mistrust against AI, the study suggests that companies should develop a code of conduct for AI in the future. According to the study participants, first initial approaches in developing an AI related code of conduct have already been developed (cf. I14.4).

As it stands, AI is confronted with both, huge excitement and apprehension. AI adoption can only be successful by appropriately guiding the society's expectations with regard to business impacts and threats (cf. I10.19). This evolving opportunity must not be wasted by a social debate disrupted between two sides either recognizing opportunities or risks only. Conversely, large parts of the society as managers, employees, associations or politicians have to recognize that traditional behaviors, habits and organizational structures are always the response to past experiences. It may also be necessary for them to evolve [6].

Not having found a concensus of what AI really is or can do, AI is already subject to regulation. While the broader debates about AI continue and additional regulatory requirements look sure to follow, firms spent huge amounts of budget on documentation and regulatory reporting. Subsequently, in the first place firms must succeed in creating space for innovation within their working environment and despite governmental regulations. Otherwise regulation will stifle innovation and give other economic areas competitive advantage.

To conclude and with regard to the environmental context our study suggests the following:

$1+2$ Desensationalize discourses around the topic of AI to overcome traditional data protection. Utilization of the "gold treasure" of proprietary data collected over the years may forearm traditional FS companies against FinTechs. Expectation management is essential to understand that AI is neither a miracle cure nor a killer robot.

3 While companies should focus on making AI trustable, explainable, and valuable to answer moral concerns, politicians should focus on digital education and define ethical standards.

4 Regulatory requirements shall leave companies enough space for creating innovation with AI. Over-regulation binds financial resources and leads to organizational inertia instead of stimulating for innovation.

\section{Discussion and Conclusion}

Modern technologies like AI do not provoke change on their own - this study demonstrates that AI adoption still opposes great demands to FS firms. Applying the TOE framework to structure the results, the analysis of the conducted interview shows that AI adoption is subject to critical success factors. These factors mainly derive from the challenges associated with the continuous digitization of all business processes and a structural change of established organizations. The derived guidelines demonstrate how employees and organizations as a whole must be able to use AI technologies in an appropriate and effective way (cf. I21.11). This study shows that AI is changing the physics of FS, weakening the bonds that have historically held together financial institutions, while creating centers of gravity where new and old capabilities have to be combined in unexperienced ways.

Tables 1 and 2 present the segregated factors and respective guidelines that were identified according to the three elements technology, organization, and envi- 
ronment. Within the technological context, the study participants suggest complexity of implementation and quality assurance issues as the major obstacles preventing banks and insurance companies from further applying $\mathrm{AI}$ in their organizations. This becomes even more relevant since finance institutions attach particular importance to stabile and reliable systems. Outdated IT architectures still complicate the use of AI applications. From an organizational perspective, the study results show a lack in AI related skills and top management support. Due to hierarchical organizational structures, banks and insurance companies miss agility and speed of reaction, which AI supported applications demand. The investigation finds that market regulations and moral concerns are slowing down the pace of AI adoption from an environmental perspective.

A central field of challenges and guidelines are related to data issues, since - more specifically - customer and transaction data are the main resource gained, processed, and maintained in the the FS industry. The study reveals that (mainly traditional) financial institutes still find it difficult to take advantage of this "gold treasure": In contrast to FinTechs, the study finds a majority of companies as still trapped in analogical mindsets. Role definitions supporting AI ("AI trainer") have to be introduced to extant IT job descriptions, in order to take advantage of AI applications. Moral concerns prohibit the use of flexible cloud solutions instead of analyzing a huge amount of proprietary data. Specified AI governance, e.g AI risk and compliance management, helps to contain the feared damage of degenerated "black box" computed AI results. As some interviewees imply, the flood of financial regulations serves as welcome excuse to stay in traditional structures rather than facing the opportunities and necessities derving from the all-encompassing digitization.

Googles announcement from "mobile first" to "AIfirst" as well as the increasing number of AI start-ups indicates that AI possibly transforms the FS industry in the future. Those businesses which fail to adapt and adopt, may find themselves undercut in turnaround times as well as costs and therefore might lose a significant amount of their market share [24]. Currently, AI is a source of both huge excitement and apprehension. AI and machine learning applications show substantial promises but also carry specific risks. Future developments of AI in the finance industry are closely linked to how quickly and sustainably the finance industry succeeds in addressing the challenges described above. Banks and insurance companies have the opportunity to incorporate their traditions and values into the ongoing technological development in order to consolidate their market position in a digital future.

As to any kind of research, this study is subject to limitations. The results derive from 22 interviews. An increased number may broaden the gained view, since a comparison with other industries may lead to increased validity. Considering the German finance industry, we believe this sample as appropriate indicator for universal results, since the regarded market is the largest in Europe with main influence for the Eurozone [7]. Future research might focus on several use cases or transform our qualitatively gained results into suitable items for further quantitative investigation.

\section{Appendix: Research Methodology}

Expanding the range of earlier studies, this analysis involves conducting and examining 22 semi-structured expert interviews in the FS industry (table 3 ).

Table 3. Interview Data Characteristics

\begin{tabular}{|c|c|c|c|}
\hline$\#$ & Group & Role & $\begin{array}{l}\text { Date/Duration } \\
\text { (min) }\end{array}$ \\
\hline 1 & Vendor & VP Customer Value Sales & $\begin{array}{l}09 / 18 / 2017 \\
43: 21 \\
\end{array}$ \\
\hline 2 & $\begin{array}{l}\text { Consulting } \\
\text { Serv.Provider }\end{array}$ & Business Manager/Speaker & $\begin{array}{l}09 / 20 / 2017 \\
50: 57\end{array}$ \\
\hline 3 & Vendor & $\begin{array}{l}\text { Head of Customer Success, } \\
\text { Portfolio Lead South Ger- } \\
\text { many }\end{array}$ & $\begin{array}{l}\text { 11/08/.2017 } \\
39: 16\end{array}$ \\
\hline 4 & $\begin{array}{l}\text { Banking/ } \\
\text { Insurance }\end{array}$ & Project Manager Insurance & $\begin{array}{l}11 / 13 / .2017 \\
34: 57 \\
\end{array}$ \\
\hline 5 & Vendor & Managing Consultant & $\begin{array}{l}11 / 14 / 2017 \\
35: 22\end{array}$ \\
\hline 6 & $\begin{array}{l}\text { Banking/ } \\
\text { Insurance }\end{array}$ & $\begin{array}{l}\text { Chief Digital Officer Bank- } \\
\text { ing }\end{array}$ & $\begin{array}{l}11 / 14 / 2017 \\
26: 33 \\
\end{array}$ \\
\hline 7 & Vendor & Regional VP FS \& Auditors & $\begin{array}{l}11 / 14 / 2017 \\
29: 37 \\
\end{array}$ \\
\hline 8 & $\begin{array}{l}\text { Banking } \\
\text { /Insurance }\end{array}$ & $\begin{array}{l}\text { Director, Senior Product } \\
\text { Manager }\end{array}$ & $\begin{array}{l}11 / 20 / .2017 \\
29: 51\end{array}$ \\
\hline 9 & $\begin{array}{l}\text { Banking/ } \\
\text { Insurance }\end{array}$ & $\begin{array}{l}\text { Head of Data Engineering } \\
\text { Banking }\end{array}$ & $\begin{array}{l}11 / 21 / .2017 \\
32: 59 \\
\end{array}$ \\
\hline 10 & $\begin{array}{l}\text { Consulting } \\
\text { ServPror } \\
\end{array}$ & $\begin{array}{l}\text { Director Big Data \& Ad- } \\
\text { vanced Analytics FS }\end{array}$ & $\begin{array}{l}11 / 22 / .2017 \\
45: 36\end{array}$ \\
\hline 11 & $\begin{array}{l}\text { Banking/ } \\
\text { Insurance }\end{array}$ & IT Manager Insurance & $\begin{array}{l}11 / 22 / 2017 \\
38: 26\end{array}$ \\
\hline 12 & $\begin{array}{l}\text { Banking/ } \\
\text { Insurance }\end{array}$ & CIO Regional State Bank & $\begin{array}{l}11 / 28 / 2017 \\
36: 36 \\
\end{array}$ \\
\hline 13 & $\begin{array}{l}\text { Consulting } \\
\text { Serv.Provider }\end{array}$ & FS Technology Consultant & $\begin{array}{l}11 / 28 / 2017 \\
28: 52 \\
\end{array}$ \\
\hline 14 & Vendor & Digital Advisor & $\begin{array}{l}12 / 04 / 2017 \\
32: 07 \\
\end{array}$ \\
\hline 15 & $\begin{array}{l}\text { Consulting } \\
\text { Serv.Provider } \\
\end{array}$ & Manager CIPS & $\begin{array}{l}12 / 05 / 2017 \\
19: 24 \\
\end{array}$ \\
\hline 16 & $\begin{array}{l}\text { Banking/ } \\
\text { Insurance }\end{array}$ & Project Manager Banking & $\begin{array}{l}12 / 05 / 2017 \\
20: 29\end{array}$ \\
\hline 17 & $\begin{array}{l}\text { Banking/ } \\
\text { Insurance } \\
\end{array}$ & Project Manager Banking & $\begin{array}{l}12 / 13 / 2017 \\
31: 25 \\
\end{array}$ \\
\hline 18 & $\begin{array}{l}\text { Consulting } \\
\text { Serv.Provider }\end{array}$ & $\begin{array}{l}\text { Head of Technology Con- } \\
\text { sulting }\end{array}$ & $\begin{array}{l}12 / 14 / .2017 \\
20: 33 \\
\end{array}$ \\
\hline 19 & Vendor & Account Manager & $\begin{array}{l}12 / 14 / 2017 \\
29: 09 \\
\end{array}$ \\
\hline 20 & $\begin{array}{l}\text { Consulting } \\
\text { Serv.Provider } \\
\end{array}$ & Senior Manager, AI Lead & $\begin{array}{l}12 / 19 / 2017 \\
37: 40 \\
\end{array}$ \\
\hline 21 & $\begin{array}{l}\text { Banking/ } \\
\text { Insurance }\end{array}$ & Digital Advisor & $\begin{array}{l}12 / 20 / 2017 \\
27: 31 \\
\end{array}$ \\
\hline 22 & $\begin{array}{l}\text { Banking/ } \\
\text { Insurance }\end{array}$ & $\begin{array}{l}\text { Head of Digital Transfor- } \\
\text { mation }\end{array}$ & $\begin{array}{l}01 / 05 / 2018 \\
24: 24 \\
\end{array}$ \\
\hline
\end{tabular}

To understand how AI influences the finance industry, three different target groups were taken into account. (1) The first group consists of leading banks and 
insurance companies, representing important players in the German finance industry. The interviewed experts were predominantly project leaders with an IT background or with specific working experience in the field of AI. The knowledge and experience of these hierarchical exposed experts ensure broader insights into the FS industry as a whole, its visions, and current challenges. (2) SAP, Microsoft, IBM, and Salesforce, four of the world's largest software manufactures represent the second group. These companies were chosen as they are specialized in offering AI products or platforms. Participants were predominantly digital advisors and specialists familiar with the company's own AI product offerings. (3) The third group consists of industrial and technology experts in the field of AI derived from a consulting service provider.

Semi-structured interviews are a useful instrument in explanatory research, because they offer an opportunity for an open exchange with the participants. This kind of examination allows to start with a similar set of pre-formulated without following a strict order during the interview, therefore leaving room for the emergence of new questions during the interview [22].

In total, about 708 minutes of interview were transcribed. For the further analysis of the transcribed data, procedures of a qualitative content analysis were executed according to Myers (2013).

\section{References}

[1] Andrews, W., "Where You Should Use AI - and Why, Gartner, United States, 2017

[2] Andrus, G., Kejrival, S., and Wadhwani, R., "Digital transformation in FS", Deloitte University Press, United States, 2017

[3] Ansari, A., and Riasi, A., "Modelling and evaluating customer loyalty using neural networks: Evidence from startup insurance companies", Future Business Journal 2, 2016, pp. 15-30

[4] Baker, J., "The Technology-Organization-Environment Framework", Integrated Series in Information Systems, Vol 28. Springer, New York, 2012

[5] Birk, F., „ Microservices: Eine State-of-the-Art Bestandsaufnahme und Abgrenzung zu SOA“, University Ulm, 2016

[6] Bitkom, „Entscheidungsunterstützung mit Künstlicher Intelligenz", 2017

[7] Bozoyan, T., „Economic Overview Germany“, Germany Trade and Invest, Berlin, 2018

[8] Chao, P.Y.K., and Tam, K.Y., "Factors Affecting the Adoption of Open Systems: An Exploratory Study", MIS Quarterly, Hong Kong, 1997

[9] Chen, N., Christensen, L., Gallagher, K., Rosamond, M., and Rafert, G., "Global Economic Impacts Associated with AI", United States, 2016

[10] Chollet, F., „,Deep Learning with Python, Manning Publications Co., 2017
[11] Etlinger, S., "The conversational business: How chatbots will reshape digital experiences, 2017, Access 03/15/.2018

[12] Gentsch, P., „Künstliche Intelligenz für Sales, Marketing und Service“, Springer Gabler, Wiesbaden, 2017

[13] Ghani, I., Niknejad N., Hussin, A., and Jeong, S., "Relationship between SOA Adoption and Performance of IT Organizations", Journal of Internet Computing and Services, Vol. 17 No. 4, 2016, pp. 173-180

[14] Graupe, D., "Principles of Artificial Neural Networks", Advanced Series in Circuits and Systems Ser., Vol. 7, No. 3, World Scientific Publishing CO Pte Ltd, 2014

[15] Groot, M., "A Primer in Financial Data Management”, Elsevier Academic Press Ltd., 2017

[16] Handelsblatt, „Das müssen Sie über MiFID II wissen“, https://www.handelsblatt.com/finanzen/anlagestrategie/trends /richtlinie-fuer-finanzinstrumente-das-mu-essen-sie-uebermifid-ii-wissen.html, 2018, Access 01/03/2018

[17] Handelsblatt, Bei der Deutschen Bank berät jetzt „Robin“, 2017, Access 02/11/2018

[18] Inn, L., "Fintech: Ecosystem and Business Models", Advanced Science and Technology Letters, Vol. 142, UNESST, 2016, pp. 57-62

[19] Krause, S. and Pellens, B., "Betriebswirtschaftliche Implikationen der digitalen Transformation", Springer Gabler, Wiesbaden, 2017

[20] Markridakis, S., "The forthcoming AI (AI) revolution: Its impact on society and firms", Elsevier, Futures 90, Cyprus, 2017, pp. 46-60

[21] Microsoft, „Versicherung goes Bot: Künstliche Intelligenz im Kundenkontakt“, 2017, Access 02/11/2018

[22] Myers, M.D., "Qualitative Research in Business and Management”, SAGE, Los Angeles, 2013

[23] Neeb, A., and Fettweiss, M., „Red Hat: Trotz Legacy IT: Die IT der Banken könnte mit Container und Microservices viel schneller sein", https://www.it-finanzmagazin.de/red-hat-trotz-legacy-it-die-it-der-banken-koenntemit-container-und-micro-services-viel-schneller-sein-47715/, 2017, Access 03/10/2018

[24] PricewaterhouseCoopers, "Sizing the Price", 2017

[25] Pröve, P.L. et al., "Automated Segmentation of Bones for the Age Assessment in 3D MR Images using Convolutional Neural Networks", Springer Vieweg, Berlin, 2017

[26] Rich, E., and Knight, K., "AI", Third Edition, Tata McGraw-Hill, United States, 1991

[27] Sauerland, A., "Von der robotergestützen Beratung bis zum Cognitive Banking, Finanzierung Leasing Factoring (FLF), Heft 4/2017, 2017, p. 180

[28] Schindler, J., "AI and machine learning in FS", Financial Stability Board (FSB), 2017

[29] Tornatzky, L.G., and Fleischer, M., "The Processes of Technological Innovation", Lexington Books, Lexington, MA, 1990

[30] Verma, S., and Bhattacharyya, S.S., "Perceived strategic-value based adoption of Big Data Analytics in emerging economy", Journal of Enterprise Information Management, Vol. 30 Issue 3, Mumbai, 2017, pp. 354-382

[31] Zhu, K., Kraemer K.L., and Dedrick, J., „Information Technology Payoff in E-Business Environments: An International Perspective on Value Creation of E-Business in the FS Industry", Journal of Management Information Systems, Vol. 21, 2004, $\quad$ pp. 17 